\title{
Application of The Theory of Planned Behavior to Generation Z and Higher Education
}

\author{
Jessica Stamp ${ }^{1}$ and Dionne Clemons" \\ ${ }^{1}$ Trinity Washington University, Washington, DC, USA \\ \#Advisor
}

ABSTRACT

The research reported in the present paper focuses on the application of the public relations function of messaging to the higher education sector. The study draws on relevant perspectives from marketing, education, psychology, and the study of Generation Z. The Theory of Planned Behavior (Ajzen, 1988) serves as the conceptual framework for this research. The homepages of the top twenty small colleges and universities, identified by College Consensus, are scrutinized using Content Analyzes. The results suggest that the values and behavior of Generation $\mathrm{Z}$ are not fully covered on each homepage analyzed; however, there is an understanding that such messaging is needed. This review calls for further theoretical work on the implementation of the Theory of Planned Behavior and reveals considerations for the virtual future of marketing for higher education.

\section{Introduction}

Millennials have remained a topic of interest surrounding the attractiveness of a product. Researchers have conducted numerous studies to exam how Millennial's think and how to capture their attention. Whether it is within sales or education, Millennials have shaped the decision factors of many of the most recent campaigns and marketing material. Recently, attention has shifted towards generation Z. Though many ties have been made between Millennials and Generation Z, the differences as notable. Generation Z is characterized as individuals born between 1995-2014 who are the children of Generation X. With a population of roughly 60 million, generation $Z$ has outnumbered Millennials. Generation $\mathrm{Z}$ is considered to be better multitaskers, they care more about money and technology, they are more loyal to their jobs, and according to a study conducted by Northeastern University, they firmly believe that college is necessary to obtain their career goals. As the first group of Generation $\mathrm{Z}$ enters the workforce and a decline in the matriculation of students rises, conversations about Generation $\mathrm{Z}$ and their effects on the future of education come into consideration. Organizations are re-evaluating how they are presenting messaging to Generation $\mathrm{Z}$ in order to attract, engage, and retain their interest. For this reason, this research proposes a qualitative study that will discover what messages are being disseminated by colleges and universities to attract Generation Z's college-age students. This research extends on previous studies of marketing, generational studies, and education.

\section{Literature Review}

Who is Generation Z, and what are they seeking?

Generation $\mathrm{Z}$ is also referred to as the "instant generation." They seek instant gratification and have an attention span of eight seconds. As the first generation to be native to technology, they are incredibly tech-savvy and view their world through small screens and multiple apps. For this reason, in 2016, the Common Application announced a partnership 
with Better Make Room national texting and social media campaign to provide high school students with personalized guidance and encouragement on how to apply to college (Loveland, 2017).

Authors Corey Seemiller and Meghan Grace conducted a study for their book Generation Z Goes to College, where they surveyed 1,200 Generation Z college students from different universities within the United States. Their findings suggest that Generation $\mathrm{Z}$ students have repeatedly received the message that they must be entrepreneurial and comfortably have adopted that mentality. They name education, employment, and racial quality as their most significant concern, more so than immigration, climate change, and legislations. They have a thoughtful worldview and want to engage in service that has a tangible and lasting impact on systematic and structural problems. Due to the era in which they were born, they are aware of troubles and traumas happening in the lives of family members, friends, and communities around the world. They are also very we-centric and are generally motivated by a desire to help and please others, and are willing to take personal risks if they believe they have more to gain (Corey Seemiller, 2016). In the realm of education, they are calculating the total cost of attendance to determine if the return is worth the investment. They are also seeking the opinions of their peers as they highly value their insight.

Despite Generations Z's acknowledgment of the importance of going to college, currently in higher education nationwide, there is a decline in the enrollment of students into undergraduate studies. According to the National Student Clearinghouse Research Center, in spring 2018, overall postsecondary enrollments decreased 1.3 percent from the previous spring. Enrollments decreased among four-year for-profit institutions (-6.8 percent), two-year public institutions (-2.0 percent), four-year private nonprofit institutions (-0.4 percent), and four-year public institutions (0.2 percent). Taken as a whole, public sector enrollments (two year and four-year combined) declined by 0.9 percent this spring. Studies suggested that these findings are the result of the current job market stability, and students are opting to work rather than to enroll in college. For those students that opted to attend college, staying in college is the concern. Financial anxieties are pressing, and it appears more beneficial for them to work than to continue their education. Generation $\mathrm{Z}$ is full of students who are realists. They have faced global terrorism, the aftermath of September 11 th, school shootings and violence, economic uncertainty, recession, and the mortgage crisis (Kaylene C. Williams, 2011). These students are concerned about their future and want to ensure that they are making the best decision today that will lead to their success tomorrow. Higher education administrators directly tie these concerns to the enrollment crisis.

Recently, enrollment has become a topic of concern for different university leaders. In a survey conducted by Gallup on behalf of Inside Higher Ed, college and university admissions directors were survived to understand how these leaders viewed higher education admissions and recruitment policies. The study was published apart of Inside Higher Ed seventh annual survey of Colleges and Universities. The results and findings reviled the following:

- A majority of admissions directors said they were very concerned about meeting their institution's enrollment goals for the coming academic year.

- Eight in 10 admissions directors say they are losing potential applicants because of concerns about student debt, including 89 percent of admissions directors at private colleges and 71 percent at public colleges.

- Admissions directors are growing increasingly concerned about the image of higher education and what that means for college admissions -- 95 percent strongly agree or agree that higher education needs to do a better job of explaining the value of a college education, up from 87 percent a year ago.

For different universities to surpass any issues surrounding enrollment, the proposed study took a look at what messages are being disseminated by universities to help eliminate this issue. Concepts of marketing, business, and psychology are combined to reach an answer.

A study conducted by Luminita Nicolescu from the Academy of Economics Studies at Bucharest focuses on how applying marketing concepts to the higher education sector can prove to be beneficial. The study discusses the extent to which marketing ideas are currently being used and what concepts of marketing are still being developed within the higher education sector. The author claims that in recent years, massive changes in policy, governance structure, and status of higher education have taken place all over the world. Environmental changes, such as privatization, diversification, decentralization, internationalization, and increased competition in higher education, are 
common to most countries. These changes have an effect on how higher education institutions operate, and they are seen as the driving forces for the marketization of higher education (Maringe, 2006). The article focus on extending previous studies by focusing on how these higher education institutions that operate as non-profits can benefit from using the marketing framework of businesses. Nicolescu positioned not only students but also employees and society as stakeholders of universities. This means that students and universities alike are not the only ones being effect by students' decisions to attend college. Employers turn to graduates to fill positions in their organizations, and society needs the expertise of these graduates to be active members of society.

Studies have also been conducted on the importance of public relations for business. PR is sometimes compared with advertising, and for this reason, PR is the least understood of all marketing tools. "The basis of PR includes using intermediaries to communicate with your audience and influence them. Those intermediaries may be industry spokespersons, stock analysts, investors, trendsetters, industry analysts, customers, employees, and the electronic and print media." (Reuben, 2008). The use of these same intermediaries has proven useful for channeling messages to Generation $\mathrm{Z}$ as they feed off of social norms, authenticity, and the opinions of influencers. These different components of public relations will be analyzed to determine which works best with generation $\mathrm{Z}$. It is predicted that the correct messaging that encompasses material that is attractive to generation $\mathrm{Z}$ and aligns with their values will help with enrollment and retention. While conducting research, the following question will be addressed:

RQ1: What messages are being disseminated by colleges and universities to influence Generation $\mathrm{Z}$ to pursue higher education?

\section{Theoretical Framework}

For this study, the Theory of Planned Behavior (TPB) is incorporated into the findings. The theory of planned behavior suggests that one's beliefs are linked to behavior. This theory of psychology proposed by Icek Ajen, states that attitude towards behavior, subjective norms, and perceived control, together shape an individual's intentions and behaviors. Behavioral beliefs are linked to the behavior of interest to expected outcomes. Attitude toward a behavior is the degree to which the performance of the behavior is positively or negatively valued. According to the expectancy-value model, attitude toward a behavior is determined by the total set of accessible behavioral beliefs linking the behavior to various outcomes and other attributes. Specifically, the strength of each belief is weighted by the evaluation of the outcome or attribute, and the products are aggregated (Icek Ajzen, 1992). Normative beliefs refer to the perceived behavioral expectations of such influential referent individuals or groups as the person's friends, peers, social media influencers, or family. It is assumed that these normative beliefs, in combination with the person's motivation to comply with the different referents, determine the subjective norm. The motivation to comply with each referent contributes to the subjective norm in direct proportion to the person's subjective probability that the referent thinks the person should perform the behavior in question (Icek Ajzen, 1992). Control beliefs have to do with the perceived presence of factors that may encourage or discourage the performance of a behavior. It is assumed that these control beliefs, in combination with the perceived power of each control factor, can determine the prevailing perceived behavioral control. The perceived power of each control factor to impede or facilitate the performance of the behavior contributes to perceived behavioral control in direct proportion to the person's subjective probability that the control factor is present. Perceived behavioral control refers to people's perceptions of their ability to perform a given behavior. Drawing an analogy to the expectancy-value model of attitude, it is assumed that perceived behavioral control is determined by the total set of accessible control beliefs, i.e., beliefs about the presence of factors that may facilitate or impede the performance of the behavior. The strength of each control belief is weighted by the perceived power of the control factor, and the products are aggregated. Behavioral control and perceived behavioral control could, together with intention, can be used to predict behavior. Intentions are an indication of a person's readiness to perform a given behavior, and it is considered to be the immediate persuader of behavior. The intention is based on attitude toward the behavior, subjective norm, and perceived behavioral control, with each predictor weighted for its importance concerning the behavior and population of interest. Behavior is the manifested, observable response in a given situation with respect to a given 
target. Single behavioral observations can be aggregated across contexts and times to produce a more broadly representative measure of behavior. In TPB, behavior is a function of compatible intentions and perceptions of behavioral control. Perceived behavioral control as a proxy for actual control is expected to moderate the effect of intention on behavior, such that a favorable intention produces the behavior only when perceived behavioral control is strong (Icek Ajzen, 1992). Successful performance of behavior depends not only on a favorable intention but also on a sufficient level of behavioral control. Actual behavioral control refers to the extent to which a person has the skills, resources, and other prerequisites needed to perform the behavior in question. In many situations, it may be difficult or impossible to determine a person's level of actual control. However, to the extent that perceived behavioral control is accurate, it can serve as an alternative for actual control and be used for the prediction of behavior. TPB was proposed to improve the theory of reasoned action that is derived from the theory of attitude. TPB is most commonly used in the fields of advertising, public relations, advertising campaigns, healthcare, and sustainability.

Concerning higher education, TPB has been used in connection to graduate studies and predicting student's intentions and application behaviors from their attitudes, subjective norms, and perceived behavioral control in relation to furthering their studies in graduate school (Ingram, 2001). Still, there is not much coverage of TPB for undergraduate enrollment.

\section{Methodology}

For this study, a content analysis was performed to determine what messages are being disseminated by different colleges and universities for recruitment purposes. In this qualitative study, content analysis allows for a general review of what these universities have identified as being significant enough to be displayed on their home pages. Previously, other scholars have used content analyses in the topic of education to gather information related to the wellbeing and nutrition of students and academic trends (transcript evaluation), but sufficient data has not been found in relevance to the collection of messaging for the intention of academic enrollment.

A study involving 20 colleges and universities websites was conducted to determine if the homepage messaging is in line with what has been determined that influences generations $\mathrm{Z}$ to attend college. The schools were selected from College Consensus top 100 small colleges. College Consensus's results are a product of combining the results of all of the most reputable college ranking publishers and thousands of real student reviews from around the web. College Consensus results are divided into two groups:

\section{Publisher Consensus}

Data was collected from reputable national and international college ranking systems that publish the raw scores behind their rankings.

\section{Student Consensus}

Data was collected from the following reputable databases that collect student's reviews of various universities

Publisher Consensus

Academic Ranking of World Universities

Center for World University Ranking

Forbes and CCAP- American's Top Colleges

Top Universities- QS World University Rankings

U.S News- National Liberal Arts Colleges Rankings

U.S. News- National University Rankings

U.S. News- Regional Colleges Midwest Rankings

U.S. News- Regional Colleges North Rankings $\underline{\text { Student Consensus }}$

Cappex

My Plan

Niche

Students Review

Unigo 


\title{
Journal of Student Research
}

\author{
U.S. News- Regional Colleges South Rankings \\ U.S. News- Regional Colleges West Rankings \\ U.S. News- Regional Universities Midwest Rankings \\ U.S. News- Regional Universities North Rankings \\ U.S. News- Regional Universities South Rankings \\ U.S. News- Regional Universities West Rankings \\ Wall Street Journal And Times Higher Education Colleges Rankings \\ Wallerbub
}

College Consensus then combines the average of a school's Publisher Consensus and Student Consensus scores to create their Top 100 Small Universities. The top 20 schools were selected, and each was then analyzed to determine if the information that is of particular interest to Generation $\mathrm{Z}$, is found on their homepages. The topics of interest were collected from data retrieved from Corey Seemiler and Meghan Grace's study on Generation Z in their book "Generation Z Goes to College." In their study, Seemiler and Grace's focus was to identify some of the essential components in better understanding this cohort of students and capture their personalities, which included common beliefs, attitudes, behaviors, and perceived membership of the group. The data was measured by connecting the theory of planned behavior to the observations.

Generation Z Topics of Interest.

$\begin{array}{ll}\text { Affordability } & \text { Virtual Technology } \\ \text { Customized College Experience } & \begin{array}{l}\text { Social Norms (current stu- } \\ \text { dent testimonials) }\end{array} \\ \text { Equality/Diversity } & \text { Service/Impact } \\ \text { Social Media } & \text { Value of Education }\end{array}$

Results were coded to determine how many of the topics of interest for Generation $\mathrm{Z}$ were found on the different university homepages. This method though general, allowed the researcher to assess what initial messages are disseminating when entering the websites.

\section{Results}

The study sought to explore what messages are being seen across different universities. Although similar in size and ranking, the colleges and universities used for the study showed their differences.

RQ1: What messages are being disseminated by colleges and universities to influence Generation $\mathrm{Z}$ to pursue higher education?

The results show that there is consistency in the messages being disseminated to prospective students and that colleges and universities are considering the factors that have been proven to influence Generation Z. However, the method in which it is being distributed may not be the most effective, considering the attention span of Generation $\mathrm{Z}$ students. When analyzing the homepages of the 20 universities and college in this study, the results show the following:

Affordability- The results show that despite higher education officials' concerns for losing potential applicants because of concerns about student debut, only 1 of the 20 universities homepages analyzed provide finical aid information. 
Customized College Experience- Only 2 of the 20 schools provided messaging about being able to craft their own major or being able to "map their academic journey."

Equality/Diversity - 6 of the 20 schools promoted images of diversity and equality in connection to course work and current faculty and student population.

Virtual Technology- 5 of 20 schools, had virtual tours. 4 of the 20 schools analyzed displayed their virtual tours on the homepage. In connection to affordability, 1 of 20 schools had cost calculators, but it was not displayed on the homepage.

Social Norms- In order to predict social norms, it was identified if the school displayed testimonials of current students and alums. 3 of the 20 schools analyzed shared these stories on their homepage.

Service/Impact- 5 of 20 schools included information on how as students, they can change the world.

Social Media Feed- 8 of 20 schools, shared real-time photos from their Instagram feeds on the homepage.

\section{Findings/Discussion}

This study found that despite the pressing concerns that higher education officials have involving Generation Z, capturing their attention within eight seconds was not adequately implemented across all the schools analyzed. It was also found that much of the needed information was encrypted into long texts or required further navigating of the website. However, many messages catered to the values of the subject generation. A concept that explains the uniformity is Content Conformity. Content conformity refers to the need to align one's content to be in accordance with the values and beliefs of their audience. The findings suggest that even though the ideologies and values of Generation $\mathrm{Z}$ are not all displayed on the homepages, there still is a need to comply with their attitude, subjective norms, and perceived behavioral control through their entire websites.

Under the focus of diversity and equality, it was found that six schools had either courses that explored different ethnic groups, images of powerful culture events, or messages that fostered inclusivity.

\section{Diversity/Equality Message}

\section{College}

Amherst College Amherst, MA

Courses Titles

Bates College

Lewiston, Maine

Colby College Waterville, Maine

homepage header image message

Grinnell College Grinnell, Iowa

messaging

\begin{abstract}
Messaging
"Introduction to Black Studies"

"Native American Literature"- (Course at Amherst College)

"Decolonizing Intellectual Traditions"

"Protest- Explore the ethnography and history of collective mobilization."
\end{abstract}

"Bates unique personality rests on the bedrock values of academic excellence, inclusivity and social responsibility".

"Silence is not an option" Sonja Thomas's family was brown-skinned in a vast ocean of whiteness

"We bring together diverse perspectives and global understanding in an open and safe community. By fostering growth, we focus our collective energy to advocate for fairness and the common good." 
Cottey College

Nevada, Missouri header messaging
"Cottey was founded by a woman who wanted to create a college where women were the center of attention. Today, almost 130 years later, that legacy continues. As a student you experience the support and connection with a sisterhood that lives on after you graduate."

There is an understanding that Generation $\mathrm{Z}$ is interested in creating a difference in the world, as 5 of the 20 schools had some form of messaging enticing students to pursue their personal impact and contribution to the world they reside.

\section{Service/Impact}

College
$\begin{aligned} & \text { Messaging } \\ & \text { Swarthmore College } \\ & \text { Swarthmore, PA }\end{aligned}$
$\begin{aligned} & \text { Davidson College } \\ & \text { Davidson, NC }\end{aligned}$
$\begin{aligned} & \text { Haverford College } \\ & \text { Haverford, PA }\end{aligned}$
$\begin{aligned} & \text { "Game changer, Inspiring leaders to transform the world" } \\ & \text { "Haverford attracts intellectually curious independent learn- } \\ & \text { ways of seeing and improving the world" }\end{aligned}$

\section{Grinnell College}

Grinnell, Iowa

"Dedicate yourself and your work to something bigger"

It was found that although all of the colleges and universities analyzed are Liberal arts schools, only two of the twenty advertised the ability to customize their studies.

\section{Customized College Experience}

College

Hamilton College

Clinton, New York
Message

"Study what you love" "Our promise, At Hamilton, study what interests you, be accepted for who you are, and prepare to be the person you were meant to become".

"Grinnellians map their own academic journeys “

Grinnell College

Grinnell, Iowa

Finally, it was found that themes were used throughout the homepages. Some of the schools had specific focuses, such as technology, eco-friendliness, sisterhood, and women empowerment. Also, although all school did not display their social media on their homepages, all had Instagram accounts that illustrated life on campus. All schools also included a list of campus events on their homepage. 


\section{Journal of Student Research}

\section{Limitations}

- Inability to use human subjects to collect data- This created issues with developing a research question, setting parameters, and the overall collection/decoding of data. It was resulted in using content analysis because it was the best way to gather information without utilizing the input of human subjects.

- Time allotted for research and overall completion of the project- The project was completed throughout a 16-week research methods course.

- The use of content analysis- Content analysis is replicable and quantitative, but it is no more objective or unchallengeable than other forms of textual analysis. It still relies on the interpretation of the text. Also, with content analysis, the categories used often do no justice to each text. For this reason, the study can easily be challenged.

\section{Future Research/Considerations}

The findings of this study call for additional research. An exploration of the effects that a lack thereof concise messaging has on university enrollment. An original content list should be composed to reflect small universities and colleges that have met enrollment goals, and small universities and colleges that have not met enrollment goals. Data should then be collected to determine if there is a direct tie between messaging and enrollment figures. In addition, Content Analyzes should be conducted from a mobile perspective, as Generation Z is more prawn to scout schools using their mobile devices.

Consider the diversity of the students in the data set. Different groups of students want, need, and may also be looking for different opportunities; therefore, regardless of generational grouping content conformity may look different depending on the demographics that school is serving. Also, consider searching for the use of subliminal messages. Generation $\mathrm{Z}$ is highly responsive to pictures that can be used to disseminate a message without the clutter of words.

Examine the virtual future of postsecondary enrollment. Concerns for an increase in environmental issues call for an increase in the strategic implementation of how to capture a prospective student's attention virtually. Consider using The Theory of Planned Behavior as a conceptual framework for the strategic planning of recruitment and retention.

\section{Conclusion}

The paper connects the application of the psychological concepts of the theory of planned behavior to messaging in higher education. The study analyzed what messages are being disseminated by colleges and universities on their websites to attract Generation $\mathrm{Z}$ students. The results show that although higher education officials are cornered about the state of higher education, they still follow antiquated advertising methods. Messages that concur with Generation Z's values, attitudes, subjective norms, and perceived control are seen throughout the websites of the schools in question, but it is to be kept in mind that they individually have eight seconds to capture the attention of this instant generation. Based on this study, it should now be accepted that applying concepts of marketing and psychology could aid in providing a better response from Generation $\mathrm{Z}$ students. This study should also be taken and extended to measure if the application of planned behavior to messaging for higher education can yield enrollment. Although the marketing field is still being developed and adapted for the higher education sector, there are still many lessons that the higher education sector can learn from marketing and the application of psychological concepts is one of them. 


\section{Journal of Student Research}

\section{References}

American Psychological Association. (2009). Publication Manual of The American

Psychological Association $6^{\text {th }}$ ed. American Psychological Association.

Berger, A. A. (2015). Media and Communication Research Methods. Boston: Sage.

Best Small Colleges | Top 100 Consensus Ranked Schools 2021. (2021, March 23). https://www.collegeconsensus.com/rankings/best-small-colleges/

Seemiller, C., \& Grace, M. (2016). Generation Z Goes To College. John Wiley \& Sons.

Hawkins, D.A., \& Lautz, J . (2005). State of College Admission: The National Association for College Admission Counseling.

Ajzen, I., \& Driver B. L. (1992). Application of the Theory of Planned Behavior to Leisure Choice. Journal of Leisure Research, 207-224.

Williams, K.C., Page, R.A. (2011). Marketing to the Generations. Journal of Behavioral Studies in Business.

Ingram, K.1., Cope, J.G. (2001). Applying to Graduate School: A Test of the Theory of Planner Behavior. Journal of Social Behavior and Personality, 216-225.

Loveland, E. (2017). Instant Generation. The Journal of College Admission.

Marcus, J. (2017). Universities and colleges struggle to stem big drops in enrollment. The Henchinger Report.

McKee, A. (2003). Textual Analysis: A beginner's Guide. Australia: Sage Publications Ltd.

Pinar, M., Trapp, P., Girard, T., \& Boyt, T. E. (2011). Utilizing the brand ecosystem for university branding. International Journal of Educational Management, 724-739.

Nicolescu, L. (2009). Applying Marketing to Higher Education: Scope and Limits. In Managment \& Marketing (pp. 35-44).

Reuben, R. (2008). The Use of Social Media in Higher Education for Marketing and Communications: A Guide for Professionals in Higer Education. State University of New York at New Paltz.

Jaschik, S., \& D. L. (2017). 2018 . ZInside Higher Ed. (2018). Term Enrollment Estimates Spring 2018.

Theus, K. T. (1994). Subliminal Advertising and The Psychology of Processing Unconscious Stimuli: A Review of Research. Psychology \& Marketing, 271-290. 


\section{Journal of Student Research}

Vedder, R. (2018, Jul). Why Enrollemtn is Shrinking At Many American Colleges.

Forbs. 